\title{
A cyber-physical systems approach to cognitive enterprise
}

\author{
Mihnea Alexandru Moisescu ${ }^{1}$, Ioan Stefan Sacala ${ }^{1}$, Ioan Dumitrache ${ }^{1}$, Simona Iuliana Caramihai ${ }^{1}$, \\ Bogdan Barbulescu', Marius Danciuc ${ }^{2}$ \\ ${ }^{1}$ Faculty of Automatic Control and Computer Science, University Politehnica of Bucharest, Romania \\ ${ }^{2}$ Digital Bit SRL, 26 Erou Ion Calin, Bucharest, Romania
}

\section{Article Info}

Received Dec $31^{\text {th }}, 2018$

\section{Keyword:}

Perception

Internet of Things

Control Architecture

\begin{abstract}
Internet of Things and Cyber-Physical Systems are paradigms that have an important influence on enterprise systems architecture and implementation. The Cognitive Manufacturing as well as the Cognitive Enterprise are emerging models, related to these paradigms, that intend to redesign in the Enterprise Information Model by integrating new information processing and problem-solving methods.

This paper intends to analyses and discuss Cognitive Enterprise enablers and principles considering an approach based on models of human brain perception-reasoning-learning processes.
\end{abstract}

\section{Corresponding Author:}

Mihnea Alexandru Moisescu

Faculty of Automatic Control and Computer Science,

University Politehnica of Bucharest,

313 Splaiul Independentei, Sector 6, Bucharest, Romania.

Email: mihnea.moisescu@upb.ro

\section{Introduction}

The research in Information and Communication Technology field need the appropriate enterprise level integration in order to be used, efficiently. New technologies such as smart devices, sensor networks, serviceoriented platforms, may be implemented in very different ways by means of complex paradigms such as Internet of Things, Semantic technologies, Data Analytics and Artificial Intelligence.

\section{Cyber-Physical Systems and Industrie 4.0}

\subsection{Future Manufacturing Systems}

A set of characteristics of the Future Enterprise Systems can be related to existing and emerging paradigms, modes and technologies such as [1] [4] [6] [9]:

- Production: Cyber-Physical Systems, Industrial Internet of Things

- Data Acquisition: Smart Things, Wireless Sensor Networks

- Management: Enterprise Modeling, Enterprise Architecture

- Data Analytics: Business Intelligence,

- Interoperability, Intelligent Documents, Adaptive Systems

- Human Resources: e-worker, Enterprise Social Networks

- Marketing: Internet of Future as "Universal Communicator", Intelligent Social Media, Virtual and Augmented Reality

- Infrastructure: Cloud Computing, Trustworthy Infrastructure,

- Information systems: IaaS or PaaS (Infrastructure/Platform as a Service), Interoperability Service

Utility (ISU), Federated, Open and Trusted Platforms (FOT), Software as a Service (SaaS), 
Automated Service Discovery and Configuration, federation of heterogeneous service-based systems (SBS), Service Science .

- Knowledge management: knowledge worker, Knowledge Representation and Semantic Modeling,

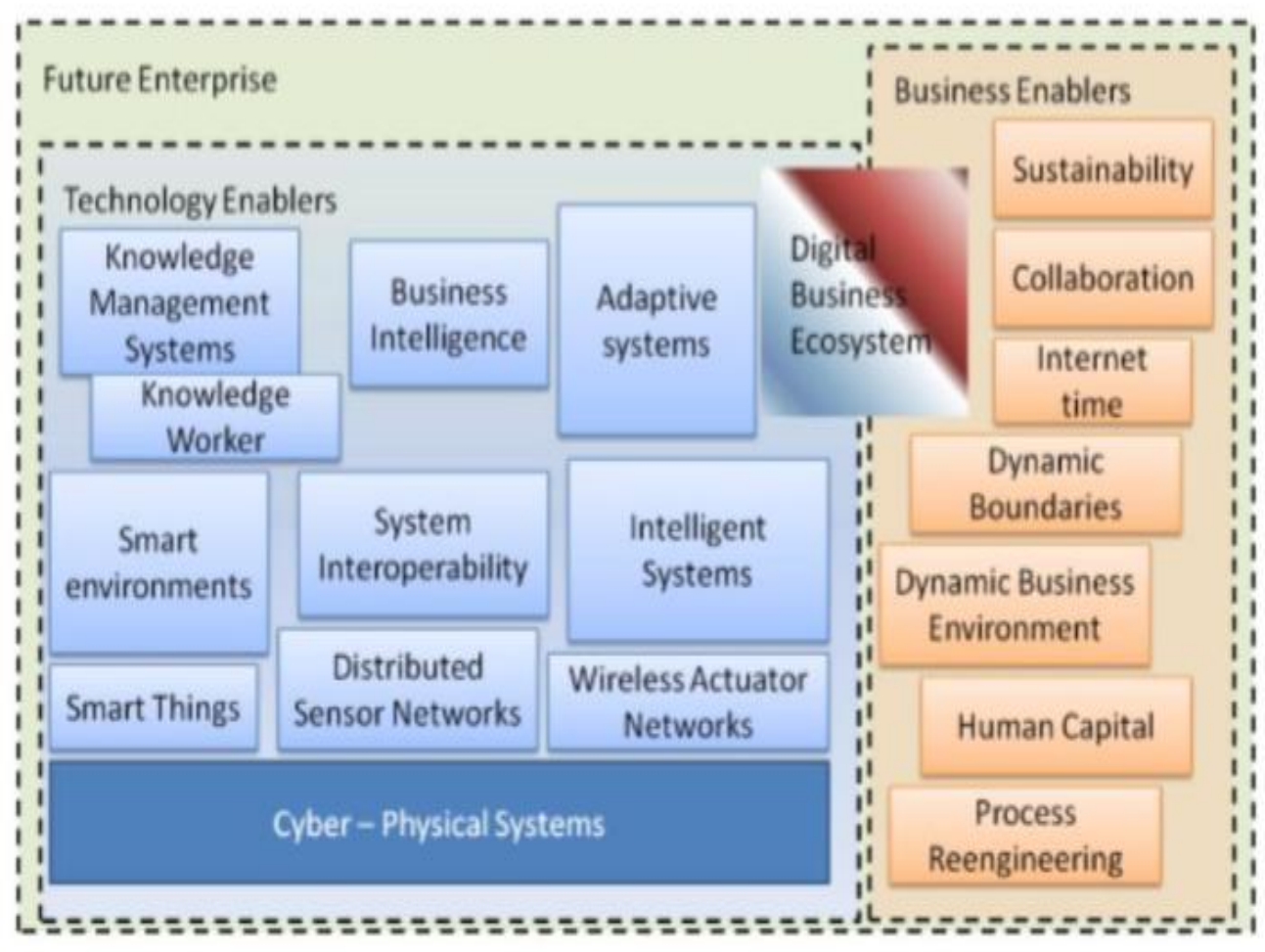

Figure 1: Future Enterprise building blocks

\subsection{Cyber-Physical Systems}

Cyber-Physical Systems ( CPS ) will transform the society as a whole as a result of "smart" humanmachine cooperation (H2M and M2M communication).

Cyber-Physical Systems are becoming ubiquitous, pervading every aspect of an individual's daily life, including: Medical care and health, Energy, Transportation and Mobility, Manufacturing, Materials and many other sectors.

Because complex systems cannot be seen as a simple set of subsystems, many different challenges and problems appeared, aspects that affect both society and industry [12]:

- The self-organization and self-management of infrastructure and utility systems;

- The smart factory, including smart processes and smart products, uses emerging architectures and business models, emphasizing interoperability;

- New technologies and integrated models and architectures are emerging (H2M and M2M) into intelligent environments.

- CPS cannot be modelled as simple systems, but from an interdisciplinary engineering perspective;

- High impact on science, technology and education.

Advances in CPS will determine the existence of faster applications, more precise, robust to hostile or inaccessible environments, performing distributed coordination of large-scale systems.

To create and implement a CPS one must consider: extending control theory in order to handle networks of devices; large-scale integration of the physical and cyber worlds; real-time operation, adaptive systems, dynamic reconfiguration and systems of systems, robust network control and network dynamics, cyber security, embedded systems, power management, CPS models and architectures, relationships, integration and interoperability as well as human in the loop. [13] [6]

Smart Factory is a key concept for Industrie 4.0 based on Cyber Physical Systems. Smart Production(highprecision, superior quality production of high-mix, low volume smart products must considered in context of Green Production(clean, resource-efficient and sustainable) and Urban Production(smart factory in the city 
close to the employees'homes we must to deliver highly innovative products with increasing product dispersion, produced economically and at high quality and high customization degree.

Therefore, the Intelligent Cyber-Enterprise will be a driver for next knowledge-based economy by integration of smart processes and smart products into a smart environment.

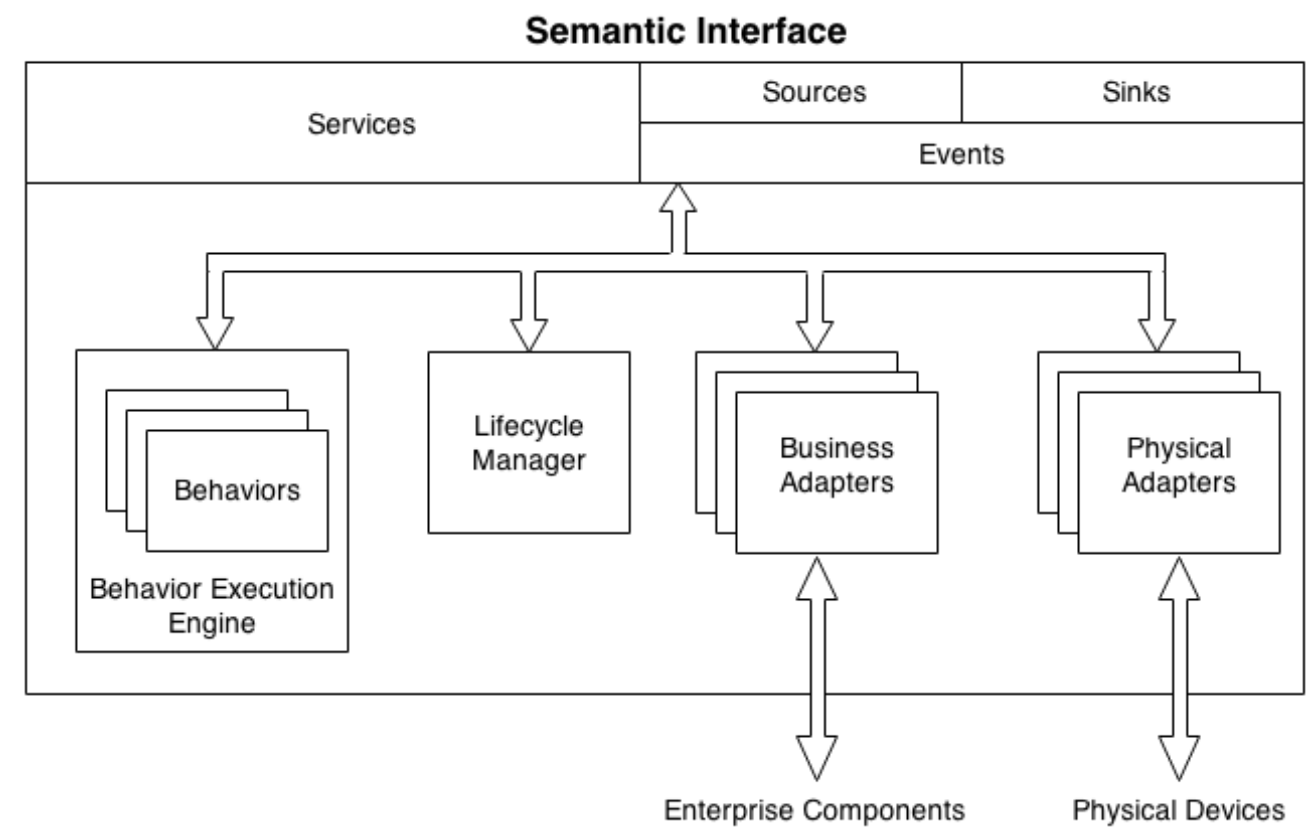

Figure. 2: Generic Cyber Intelligent Enterprise System Architecture

An implementation of a CPS systems architecture comprising of the following sunbistems is discussed in [6] [14]:

- Semantic interface - provides a unique way of accessing both virtual and physical resources of the system.

- Physical adapters - the Intelligent Entities can also host a set of adapters for the physical devices.

- Behaviour Execution Engine - instances of intelligent Entities will be able to execute behaviors

- Lifecycle Manager - handles all aspects of the Intelligent Entity's lifecycle

\section{From Cognitive Computing to Cognitive Manufacturing and Cognitive Enterprise}

\subsection{Cognitive Manufacturing}

Cognitive Manufacturing integrates IoT principles, Artificial intelligence and data analytics technologies. The objective is to exploit manufacturing process as well as enterprise wide data and information, as to achieve [7]:

- optimal use assets and equipment

- processes reengineering by integrating decision-making models and data analytics methods for workflows and working environment

- enterprise wide knowledge management

Cognitive manufacturing systems are emerging and address the following relevant aspects [2], [5], [11]:

- improvement of product quality and by using and integrating enterprise and environment focused approach

- adaptive systems integration

- analyzing manufacturing data obtained from sensors: production management systems are generating huge amounts of manufacturing data

- integrating manufacturing systems decision making models with business intelligence systems

- integrating knowledge management systems at enterprise level: cognitive enterprise is considering linking the overall decision-making procedures of the enterprise 


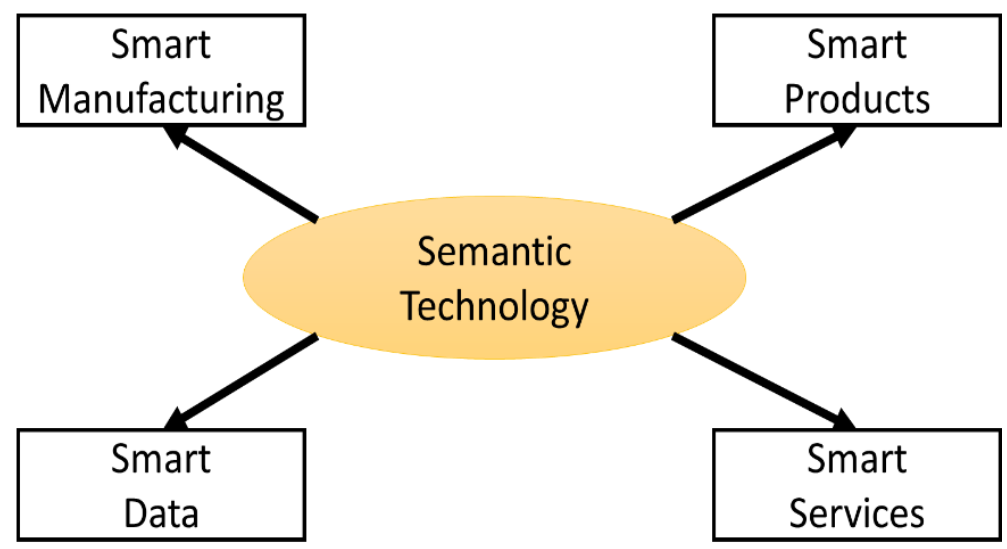

Figure 3: Smart technologies

\subsection{Cognitive Enterprise}

Relevant characteristics of Cognitive Enterprise are presented in the following [3],[8],[10]:

- Cognitive technologies

- Cognitive Robotic Process Automation

- Learning enterprise

- Composable organization

- Sensing capability

- Adaptability

- Cognitive enterprise data architecture

- Machine learning

- Deep learning

Factories of Future (FoF) will integrate all paradigms like; Cognitive Enterprise (Knowledge interoperability), Biological Manufacturing, Intelligent Manufacturing Systems(smart equipments, smart processes, smart products...) to create an Intelligent Cyber- Enterprise with emergent behavior.

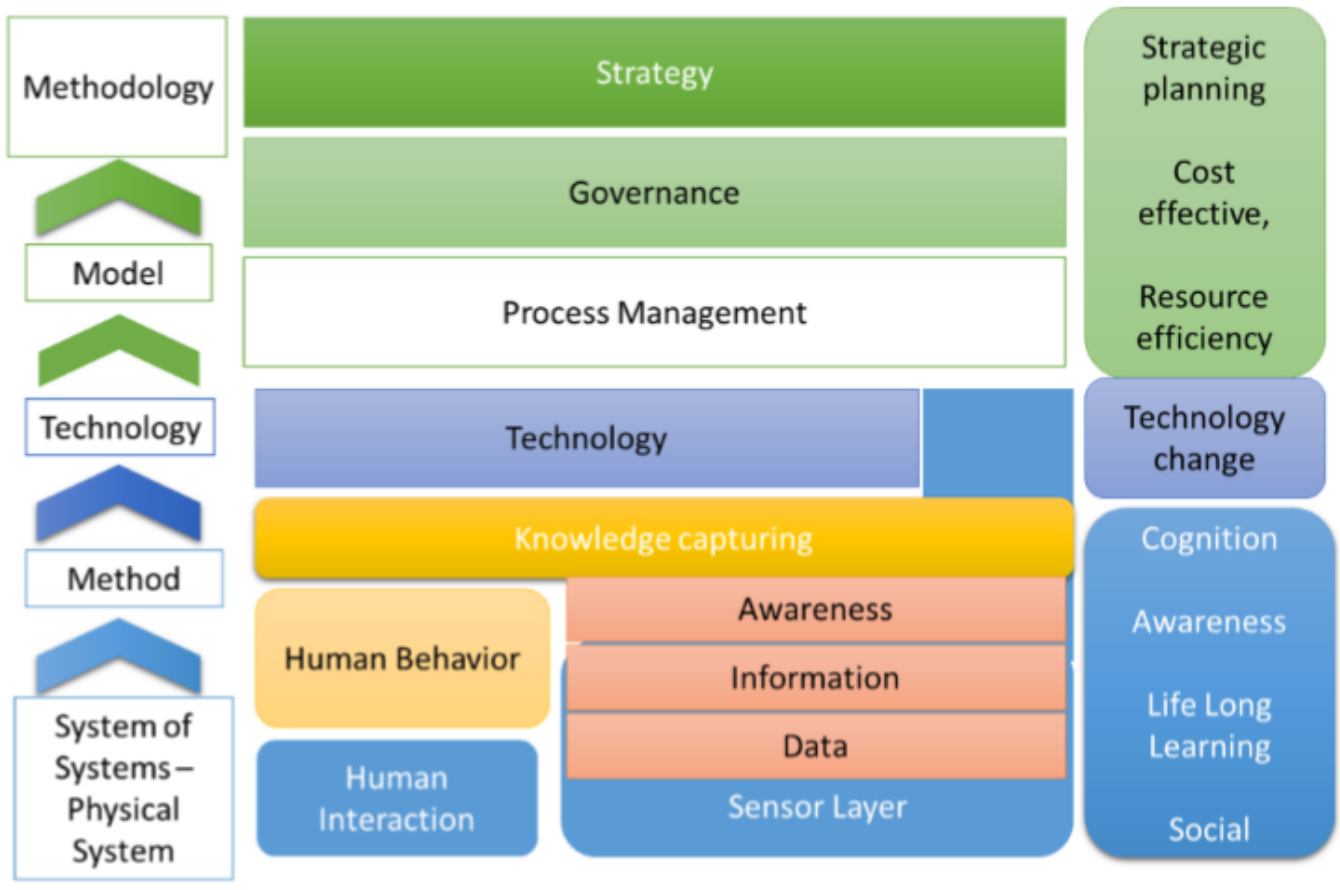

Figure 4: Cognitive Enterprise model

\section{Case Study}

Predictive maintenance Systems are becoming a necessity for current Manufacturing equipment and can be integrated in Cognitive Manufacturing Systems and extended towards Cognitive Enterprise Systems. [6] 
Cognitive Manufacturing Systems can integrate Predictive Maintenance Sub-systems that can be related to the islands of CPS models.

A Predictive Maintenance Platform enables the integration the Predictive Maintenance Components associated to Manufacturing Equipment. Such components can be integrated with the aid of Object abstraction interfaces, Domain representation interfaces and Information processing interfaces.

A production process model integrating Predictive Maintenance Sub-systems is presented in the figure below. In order allow event acquisition system to be extended to integrate geographically distributed production systems a device capable of connecting remote locations and monitoring equipment has been used.

The device offers redundant and resilient data transition by switching between GSM and satellite modems. The data acquired from each equipment can be transmitted to an enterprise level predictive maintenance system.

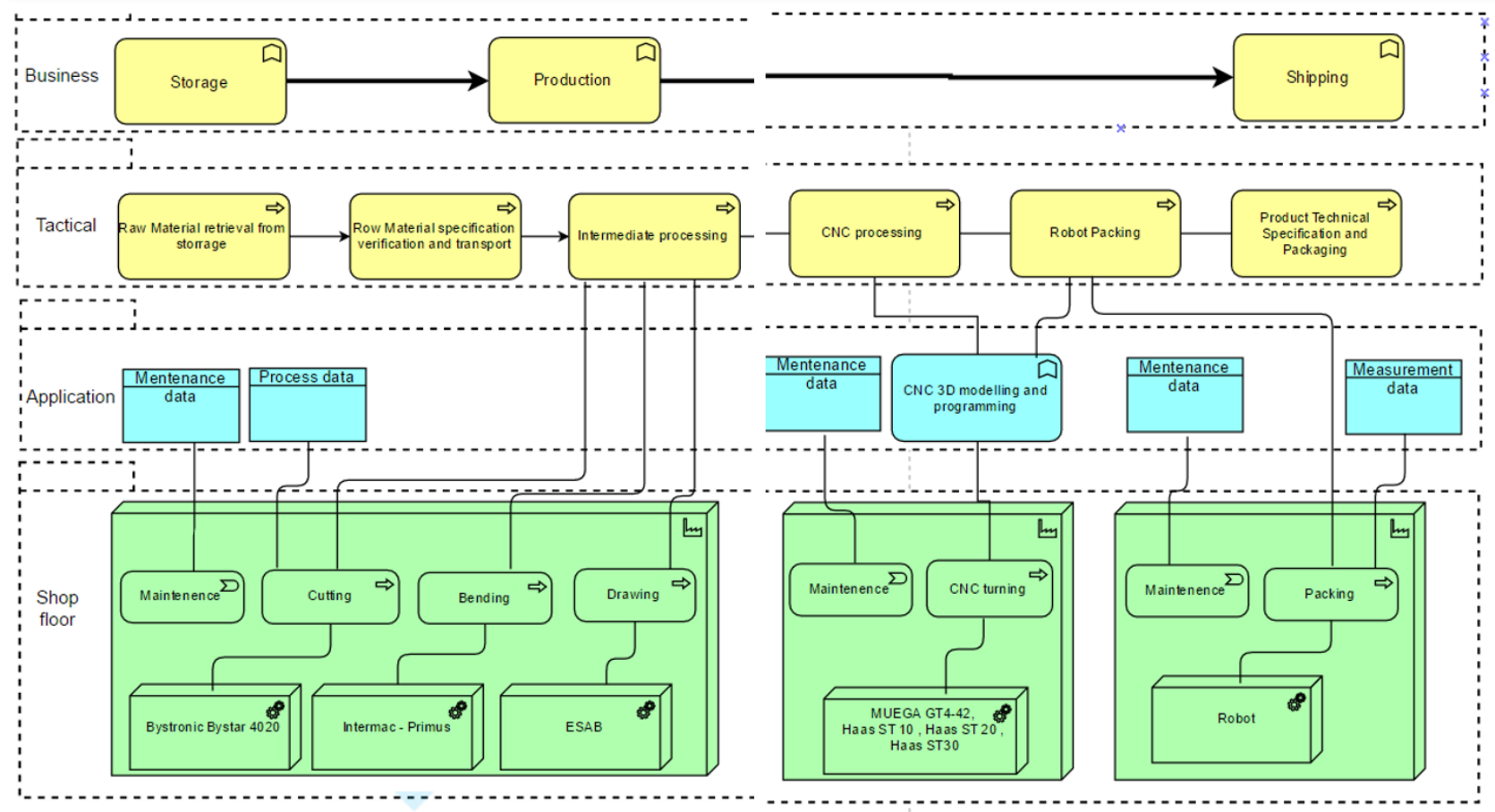

Figure 5: As-is production process generic diagram including business, application and technology view

\section{Conclusion}

Based on the recent developments in various research fields such as Cyber Physical Systems, Internet of Things and Semantic Web, in this article, we propose a new vision that enables the integration of physical components and human resources with business processes in Enterprise Systems.

The adoption of this type of system can have a significant positive impact as it creates new business opportunities and increases the agility of companies.

\section{Acknowledgements}

This research was supported/partially supported by POC contract 53/05.09.2016, ID 40 270, MySMIS 105976 Ecosystem for ICT Research, Innovation, Product and Service Development for a Internet of Things Interconnected Society - NETIO , subsidiary contract 1265 / 22.01.2018, Development of an Innovative Solution for Efficient Communication in an Industrial Environment - DIVE.

\section{References}


[1] Dimon, Catalin, and Andreea Ioana Udrea. "Compartmental networks approach on urban traffic control." In System Theory, Control and Computing (ICSTCC), 2013 17th International Conference, pp. 166-171. IEEE, 2013.

[2] Ezry, R., Haydock, M., Tyler, B., Shockley, R., "Analytics: Dawn of the cognitive era - How early adopters have raised the bar for data-driven insights." October 2016. http://www.ibm.com/services/us/gbs/thoughtleadership/2016analytics/

[3] Foster Mark, 2018, The Cognitive Enterprise Part 1 - The journey to AI and the rise of platform-centric business architectures IBM Institute for Business Value, https://www01.ibm.com/common/ssi/cgibin/ssialias?htmlfid=GBE03910USEN

[4] Marques, M., Agostinho, C., Zacharewicz, G., Poler, R. and Jardim-Goncalves, R., 2018. Responsive Production in Manufacturing: A Modular Architecture. In Practical Issues of Intelligent Innovations (pp. 231-254). Springer, Cham.

[5] Pureswaran, V, Burnett, S., Anderson, B., "The Business of Things: Designing successful business models in the cognitive Internet of Things." IBM Institute for Business Value. December 2015, www.ibm.biz/businessofthings

[6] Repta, Dragos, Mihnea Alexandru Moisescu, Ioan Stefan Sacala, Ioan Dumitrache, and Aurelian Mihai Stanescu. "Towards the development of semantically enabled flexible process monitoring systems." International Journal of Computer Integrated Manufacturing 30, no. 1 (2017): 96-108.

[7] Şandru, O., Vlădareanu, L., Şchiopu, P., Vlădareanu, V., Şandru, A., (2013) Multidimensional Extenics Theory, 75 (1), pp. 3-12., U.P.B. Sci. Bull., Series A, ISSN 1223-7027;

[8] Schatsky, D., Muraskin, C. and Iyengar, K., 2016. Robotic Process Automation: A Path to the Cognitive Enterprise.

[9] Vladareanu, L., Curaj, A., Munteanu, R.I., Complex Walking Robot Kinematics Analysis And Plc MultiTasking Control (2012) Rev. Roum. Sci. Techn. - Électrotechn. et Énerg., 57 (1), pp. 90-99;

[10] Vladareanu, L., Iliescu, M., Wang, H., Yongfei, F., Vladareanu, V., Yu, H. and Smarandache, F., 2016, November. CSP and "omics" technology apllied on versatile and intelligent portable platform for modeling complex bio-medical data. In Advanced Mechatronic Systems (ICAMechS), 2016 International Conference on (pp. 423-428). IEEE.

[11] Zhang, J., (2017), Cognitive manufacturing \& Industry 4.0, Internet of Things blog.

[12] Mocanu, Ştefan, Ramona Din, Daniela Saru, and Cosmin Popa. "Using graphics processing units for accelerated information retrieval." Studies in Informatics and Control 23, no. 3 (2014): 249-256.

[13] Dumitrache, Ioan, Simona Iuliana Caramihai, and Aurelian Stanescu. "From mass production to intelligent cyber-enterprise." In 2013 19th International Conference on Control Systems and Computer Science, pp. 399-404. IEEE, 2013.

[14] Sacala, Ioan Stefan, Mihnea Alexandru Moisescu, and Dragos Repta. "Towards the development of the future internet based enterprise in the context of cyber-physical systems." In 2013 19th International Conference on Control Systems and Computer Science, pp. 405-412. IEEE, 2013. 